\title{
Inhaled Nanoparticles Accumulate at Sites of Vascular Disease
}

Mark R. Miller, ${ }^{*}{ }^{\dagger, \infty}, \nabla_{\text {@i] }}$ Jennifer B. Raftis ${ }^{\dagger, \infty}, \nabla$ Jeremy P. Langrish, ${ }^{\dagger}$ Steven G. McLean, ${ }^{\dagger}$ Pawitrabhorn Samutrtai, ${ }^{\S}$ Shea P. Connell, ${ }^{\dagger}$ Simon Wilson, ${ }^{\dagger}$ Alex T. Vesey, ${ }^{\dagger}$ Paul H. B. Fokkens, ${ }^{\|}$ A. John F. Boere, $\|$ Petra Krystek, ${ }^{\perp}$ Colin J. Campbell, ${ }^{\S}$ Patrick W. F. Hadoke, ${ }^{\dagger}$ Ken Donaldson, ${ }^{\ddagger}$ Flemming R. Cassee, ${ }^{\|, \#}$ David E. Newby, ${ }^{\dagger}$ Rodger Duffin, ${ }^{\ddagger, \nabla}$ and Nicholas L. Mills ${ }^{\dagger, \nabla}$

${ }^{\dagger}$ BHF Centre for Cardiovascular Science, ${ }^{\ddagger}$ MRC Centre for Inflammation Research, and ${ }^{\S}$ EaStCHEM School of Chemistry, University of Edinburgh, Edinburgh EH16 4TJ, United Kingdom

"National Institute for Public Health and the Environment (RIVM), 3721 MA Bilthoven, The Netherlands

${ }^{\perp}$ Department of Environment and Health, VU University, $1081 \mathrm{HV}$ Amsterdam, The Netherlands

\#Institute for Risk Assessment Sciences, Utrecht University, 3512 JE Utrecht, The Netherlands

\section{Supporting Information}

ABSTRACT: The development of engineered nanomaterials is growing exponentially, despite concerns over their potential similarities to environmental nanoparticles that are associated with significant cardiorespiratory morbidity and mortality. The mechanisms through which inhalation of nanoparticles could trigger acute cardiovascular events are emerging, but a fundamental unanswered question remains: Do inhaled nanoparticles translocate from the lung in man and directly contribute to the pathogenesis of cardiovascular disease? In complementary clinical and experimental studies, we used gold nanoparticles to evaluate particle translocation, permitting detection by high-resolution inductively coupled mass spectrometry and Raman microscopy. Healthy volunteers were exposed to nanoparticles by acute inhalation, followed by repeated sampling of blood and urine. Gold was
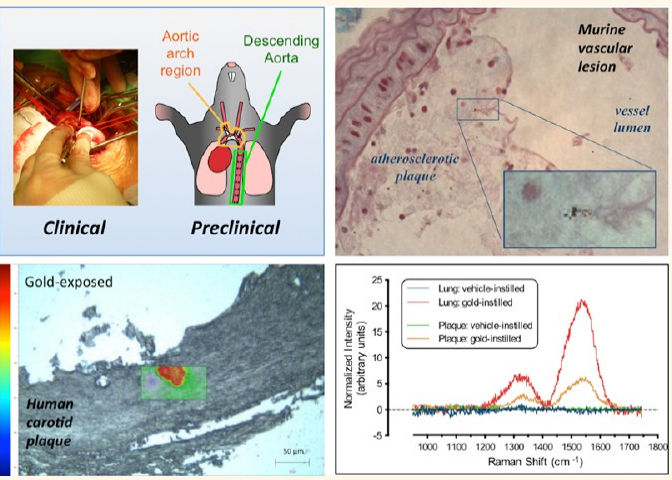
detected in the blood and urine within $15 \mathrm{~min}$ to $24 \mathrm{~h}$ after exposure, and was still present 3 months after exposure. Levels were greater following inhalation of $5 \mathrm{~nm}$ (primary diameter) particles compared to $30 \mathrm{~nm}$ particles. Studies in mice demonstrated the accumulation in the blood and liver following pulmonary exposure to a broader size range of gold nanoparticles (2-200 $\mathrm{nm}$ primary diameter), with translocation markedly greater for particles $<10 \mathrm{~nm}$ diameter. Gold nanoparticles preferentially accumulated in inflammation-rich vascular lesions of fatfed apolipoproteinE-deficient mice. Furthermore, following inhalation, gold particles could be detected in surgical specimens of carotid artery disease from patients at risk of stroke. Translocation of inhaled nanoparticles into the systemic circulation and accumulation at sites of vascular inflammation provides a direct mechanism that can explain the link between environmental nanoparticles and cardiovascular disease and has major implications for risk management in the use of engineered nanomaterials.

KEYWORDS: nanoparticle, translocation, gold, air pollution, cardiovascular, atherosclerosis

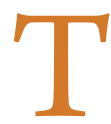

he manufacture of nanomaterials is growing exponentially and with this so is the potential for human exposure. The fate of engineered nanoparticles and effect on health following exposure are largely unknown., ${ }^{1,2}$ Since manufactured nanoparticles of different types vary in their ability to cause inflammation and toxicity in animal studies, ${ }^{3}$ we may anticipate heterogeneity in their impact on humans at plausible exposure. Given the prominent cardiovascular effects of nanosized particulate matter in air pollution, our limited understanding of the potential cardiovascular effects of engineered nanoparticles, in particular, is a pressing concern. ${ }^{4}$
Air pollution is a major public and environmental health issue contributing to up to 7 million premature deaths worldwide each year. ${ }^{5,6}$ The adverse effects of particulate air pollution on cardiovascular health have been established in a series of major epidemiological studies, ${ }^{7,8}$ and even transient exposure to high levels of air pollution may trigger an acute cardiovascular event. ${ }^{9}$ Nanosized particulate matter in air

Received: December 21, 2016

Accepted: March 24, 2017

Published: April 26, 2017 
A

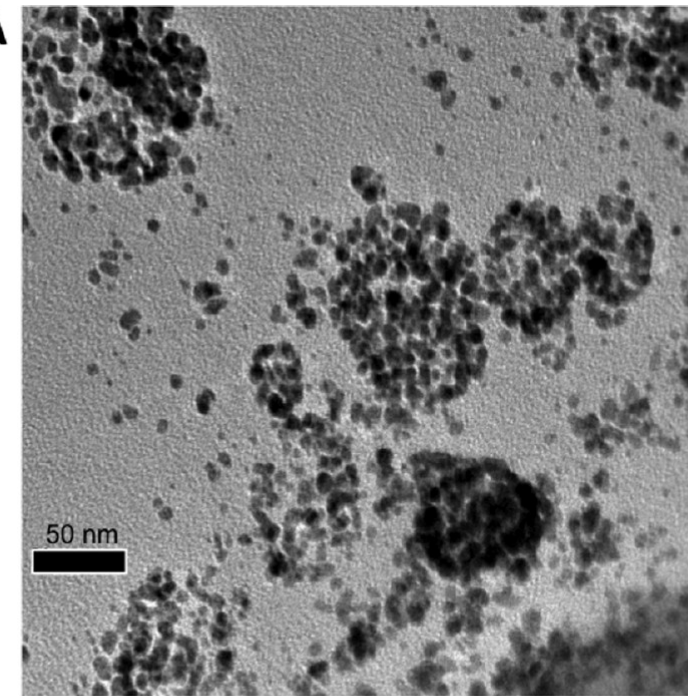

C

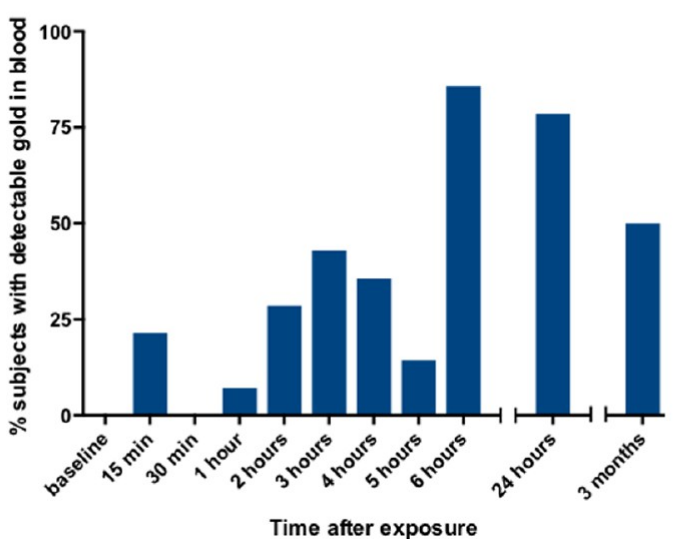

B

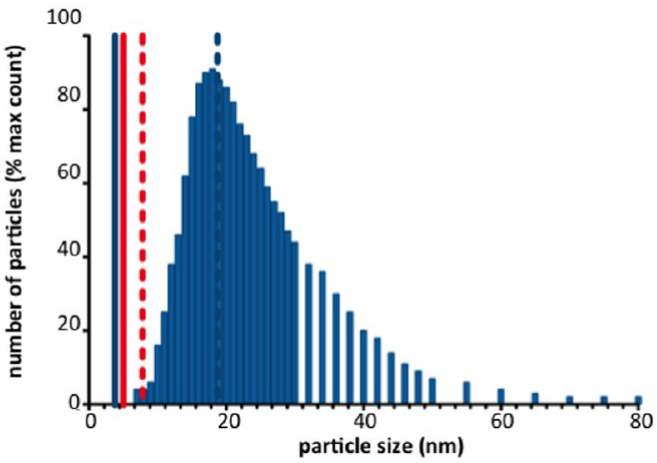

Clinical Study Median particle size

- Spark generated gold primary particle size (AFM) $=3.8 \mathrm{~nm}$

--- Aerodynamic count median diameter (SMPS) $=18.7 \mathrm{~nm}$

Murine Study Median particle size

Gold colloid (primary particle size $($ TEM) $=5.0 \mathrm{~nm}$

--- Gold colloid in PBS suspension (DLS) $=7.8 \mathrm{~nm}$

D



Figure 1. Gold nanoparticle translocation in man. (A) Representative transmission electron micrograph showing gold particles generated by the spark generator with a primary particle size of $3.8 \mathrm{~nm}$ in loose agglomerates (B) with an aerodynamic count median diameter of $18.7 \mathrm{~nm}$ (geometric standard deviation = 1.5). Abbreviations: AFM = atomic force microscopy; DLS = dynamic light scattering; SMPS = scanning mobility particle sizer; and TEM = transmission electron microscopy. (C) In man, gold was detectable in the bloodstream in some subjects within $15 \mathrm{~min}$ of the $2 \mathrm{~h}$ exposure and was detectable in the majority of subjects at $24 \mathrm{~h}(12 / 14$ subjects, 86\%). (D) Quantification of gold concentrations in blood and urine. Blood concentrations were close to the limit of quantification $(0.03 \mathrm{ng} / \mathrm{g}$ of blood; dotted line) at early time points. Gray symbols represent values below the limit of quantification, but above the limit of detection $(0.01 \mathrm{ng} / \mathrm{g}$ of blood). Data expressed as median \pm interquartile range.

pollution, such as that derived from vehicle exhaust, remains a major public health concern. ${ }^{10,11}$ We have previously demonstrated that acute exposure to diesel exhaust causes vascular dysfunction, thrombosis, and myocardial ischemia in healthy individuals and in patients with coronary heart disease. $^{12,13}$ Chronic exposure to particulate air pollution is associated with the development and progression of the vascular disease atherosclerosis in animals and man. ${ }^{14,15}$ While these observations are important, a major area of uncertainty remains: How do inhaled particles influence the pathogenesis of systemic cardiovascular disease? Are inhaled nanoparticles able to translocate into the circulation and directly contribute to cardiovascular disease?

Inhaled nanoparticles are able to deposit deep in the lungs where they induce oxidative stress and inflammation. ${ }^{16,17}$ It has been hypothesized that inflammatory mediators pass into the systemic circulation ${ }^{18}$ and indirectly influence the cardiovascular system. However, evidence of systemic inflammation following exposure is inconsistent and rather modest. An alternative hypothesis is that inhaled nanoparticles penetrate the alveolar epithelium and translocate into the circulation and directly contribute to cardiovascular disease. ${ }^{19,20}$ It has been speculated that these processes may be accelerated by inflammation, through increased permeability of the alveolar wall or through assisted translocation within macrophages. ${ }^{21-23}$ Evaluation of nanoparticle translocation following inhalation exposure is challenging because of the small size of particles, the low deposited mass, and the requirement for extremely sensitive and specific methods of detection. Previous studies in man have been inconsistent due to leaching of radiolabel from nanoparticles. ${ }^{24,25}$ While there is no evidence to date that translocation occurs in man, animal studies have provided more compelling evidence that nanoparticles are able to translocate. $^{20,26,27}$ Oberdorster and Kreyling report translocation and accumulation of particles in the liver. ${ }^{28,29}$ Whether this occurs in man and whether those particles entering the circulation interact with the cardiovascular system is unknown, especially in relation to areas of the vasculature that are susceptible to disease where their biological activity is of greatest risk. 

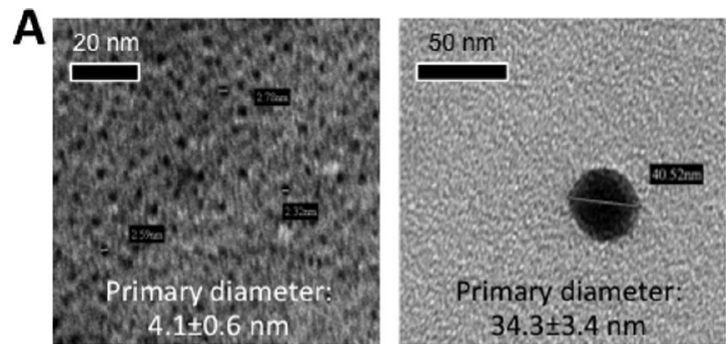

B

\begin{tabular}{|c|c|c|}
\hline Parameter & Small particles & Large particles \\
\hline Mass, $\mu \mathrm{g} . \mathrm{m}^{-3}$ & $192 \pm 11$ & $146 \pm 36$ \\
\hline Particle Count, \#. $\mathrm{cm}^{-3}$ & $41.5 \pm 2.3 \times 10^{5}$ & $1.34 \pm 0.04 \times 10^{5}$ \\
\hline Primary particle diameter, $\mathrm{nm}$ & $4.1 \pm 0.6$ & $34.3 \pm 3.4$ \\
\hline Aerodynamic count median diameter, $\mathrm{nm} / \sigma_{\mathrm{sd}}$ & $17.8 / 1.2$ & $52.4 / 1.4$ \\
\hline Temperature, ${ }^{\circ} \mathrm{C}$ & $22.0 \pm 0.7$ & $21.5 \pm 0.8$ \\
\hline Relatively humidity, $\%$ & $28.8 \pm 3.5$ & $33.0 \pm 6.3$ \\
\hline
\end{tabular}

C

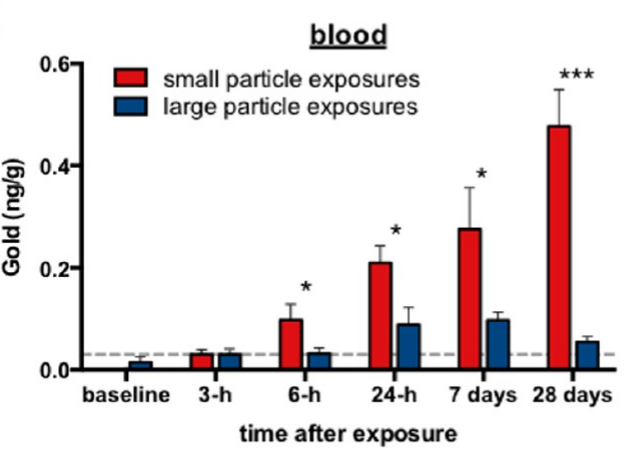

D
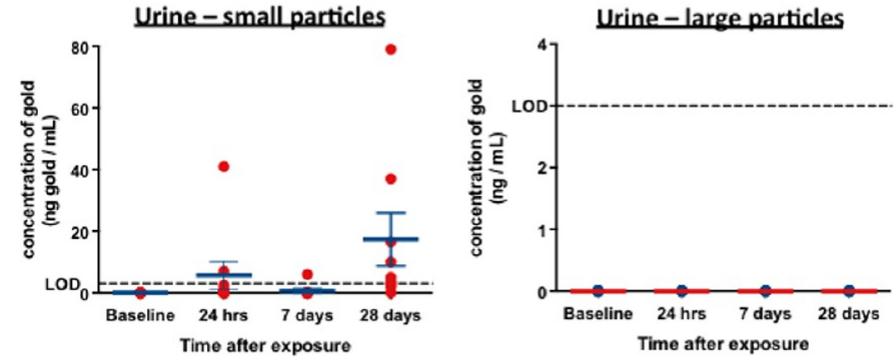

E

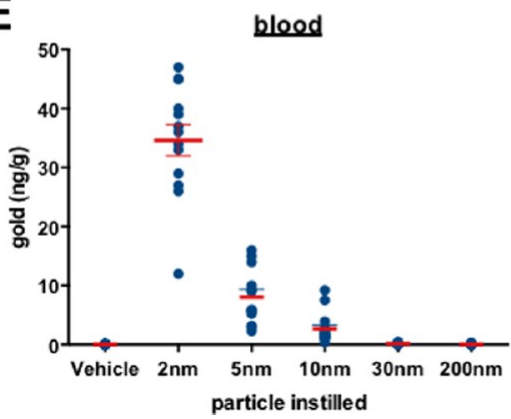

F

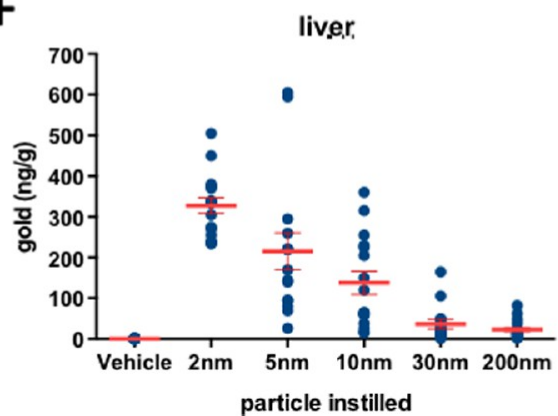

G

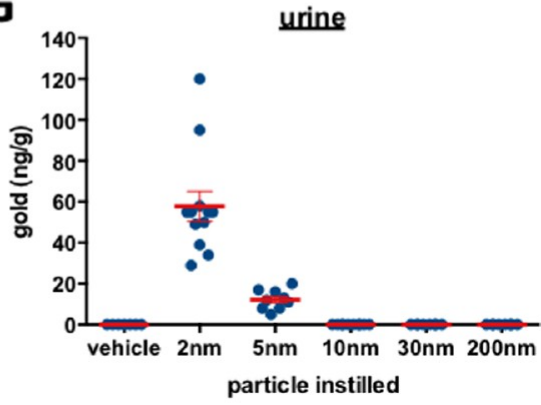

Figure 2. Effect of particle size on translocation. (A) Representative transmission electron micrograph showing gold particles (4 $\mathrm{nm}$ primary diameter) generated by the spark generator (i) with and (ii) without particle fusing to obtain large ( 34 nm primary diameter $)$ particulates from the second clinical exposure study. (B) Characteristics for aerosolized gold particle exposures in clinical studies. (C) Levels of gold detectable in the bloodstream in subjects exposed to different sizes of gold particles. (D) Levels of gold detectable in the urine of subjects exposed to different sizes of gold particles. (E) Levels of gold in the blood of mice exposed to 5 weeks of repeated pulmonary instillation with different sizes of gold nanoparticles. (F) murine liver. (G) murine urine. Data expressed as mean \pm SEM, unless otherwise stated.

Here we use complementary clinical and experimental studies to address whether inhaled nanoparticles translocate from the lung into the circulation. Gold nanoparticles are used as model nanoparticles that are, available in relevant size ranges, effectively inert for controlled human exposure and to facilitate detection of low levels in systemic tissues through specific highsensitivity techniques. We hypothesize that inhaled nanoparticles will gain access to the bloodstream and accumulate at sites of vascular inflammation.

\section{RESULTS AND DISCUSSION}

Particle Translocation in Man. Fourteen healthy male volunteers were exposed to gold nanoparticles (median primary particle size of $3.8 \mathrm{~nm}$, present in loose agglomerates of 18.7 $\mathrm{nm}$ (geometric standard deviation: 1.5; Figure 1A,B) by inhalation $\left(116 \pm 12 \mu \mathrm{g} / \mathrm{m}^{3} ; 5.8 \pm 0.3 \times 10^{6}\right.$ particles $\left./ \mathrm{cm}^{3}\right)$ for $2 \mathrm{~h}$ during intermittent exercise (Supplementary Figure S1). Gold exposure was well tolerated and there were no adverse effects on lung performance (data not shown).
Blood and urine samples were obtained throughout the first $24 \mathrm{~h}$ and at 3 months. No volunteer had gold detectable in the bloodstream prior to exposure, but gold was detectable as early as $15 \mathrm{~min}$ after exposure in some subjects and was present in the majority (12/14 subjects, $86 \%)$ at $24 \mathrm{~h}$ (Figure $1 \mathrm{C})$. There was no evidence of a significant time-dependent increase in gold concentration in the blood within the first $6 \mathrm{~h}$ of exposure (Figure 1D). Gold was still detectable in blood and urine at 3 months.

Particle Translocation Is Dependent on Particle Size. To explore if the particle size affected their ability to translocate, we exposed healthy volunteers to gold particles with a primary particle size of either $\sim 4 \mathrm{~nm}(4.1 \pm 0.6 \mathrm{~nm}$ primary diameter) or $34 \mathrm{~nm}$ (34 $\pm 3 \mathrm{~nm}$ primary diameter) ( $n$ $=10$ and 9 volunteers, respectively; Figure 2A,B). Particles agglomerated in the aerosol to a median aerodynamic diameter of 18 and $52 \mathrm{~nm}$, respectively (Figure 2B). Gold was detectable in the blood at low levels following inhalation of either size of particle, although levels of the smaller particle were far greater (Figure 2C). Gold was detectable in the urine following 
exposure to $4 \mathrm{~nm}$ particles, but not in the urine of volunteers exposed to the larger particulate (Figure 2D).

To address tissue accumulation over a wider range of particle sizes, we repeatedly instilled mice with $2,5,10,30$, or $200 \mathrm{~nm}$ gold nanoparticles (primary particle size). Gold was detectable in the blood following exposure to each size of particulate. However, the incidence of detectable gold, and the concentration of gold, in the blood was far greater following exposure to the smaller particles (Figure $2 \mathrm{E}$ ). A threshold of particle accumulation (based on the limit of detection using HR-ICPMS) was observed for a primary diameter of 10-30 $\mathrm{nm}$. Particle accumulation in the liver also followed a similar trend (Figure $2 \mathrm{~F}$ ), but gold was only detectable in the urine following exposure to particles $\leq 5 \mathrm{~nm}$ (Figure 2G).

Accumulation of Translocated Particles at Sites of Vascular Inflammation. Given the close association of nanoparticles with phagocytic inflammatory cells, we wished to explore whether inhaled nanoparticles accumulate at sites of vascular inflammation. Apolipoprotein $\mathrm{E}$ knockout mice $\left(\mathrm{ApoE}^{-/-}\right)$were used as a well-established model of atherosclerosis and fed a high-fat diet to accelerate the development of vascular lesions. Intratracheal administration of gold nanoparticles (diameter $5 \mathrm{~nm}$; BBInternational, U.K.; Figure 3A) or vehicle was conducted twice weekly for 5 weeks to deliver a total of $110 \mu \mathrm{g}$ of gold nanoparticles. Blood and liver samples were taken $24 \mathrm{~h}$ after the last instillation, and the aortic arch and descending aorta were harvested as areas exhibiting and free from atherosclerosis, respectively.

Instillation of gold nanoparticles was associated with a mild pulmonary inflammatory response (Figure 3B). At autopsy, gold nanoparticles were present in the alveoli and largely contained within macrophages (Figure 4A,B). Gold was detected in the blood of gold-instilled mice at concentrations of $9.4 \pm 1.2 \mathrm{ng} / \mathrm{mL}$, compared with $0.4 \pm 0.2 \mathrm{ng} / \mathrm{mL}$ in vehicleinstilled mice $(P<0.0001$; Figure $3 C)$. Gold also accumulated in the liver (Figure 3C).

The aortic arch from ApoE $\mathrm{E}^{-/-}$mice developed complex atherosclerotic plaques rich in lipids and macrophage-derived foam cells. Gold concentrations in the aortic arch were 10-fold higher in gold-treated compared to vehicle-treated mice $(60 \pm$ 24 vs $6 \pm 1 \mathrm{ng} / \mathrm{g}$ of tissue; $P=0.023)$ and exceeded concentrations in the descending thoracic aorta $(12 \pm 6 \mathrm{ng} / \mathrm{g}$ of tissue; Figure 3D). Isolated histological sections of atherosclerotic plaque from gold-treated animals revealed the presence of clusters of red-purple granules within foam cells (Figure 4C) similar in appearance to nanoparticles in suspension. Particulate clusters were seen on transmission electron micrographs of atherosclerotic plaque from goldtreated mice that were distinct from commonly demonstrated electron-dense membranous structures (Figure 4D and Supplementary Figure S2). The presence of particulate gold within atherosclerotic plaques was confirmed on silveraugmented arterial sections of gold-treated, but not vehicletreated, mice using Raman spectroscopy (Figure 5 and Supplementary Figure S3).

In patients with a recent cerebrovascular accident scheduled to undergo carotid endarterectomy, we evaluated particle translocation and accumulation at sites of atherosclerosis (Figure 6A). Twelve patients were recruited, of which three were exposed to gold nanoparticles $(5 \mathrm{~nm})$ for $4 \mathrm{~h}$ under resting conditions $24 \mathrm{~h}$ prior to undergoing surgery. Gold was measurable at concentrations above the limit of quantification in blood from a single patient and urine from 2 patients
A

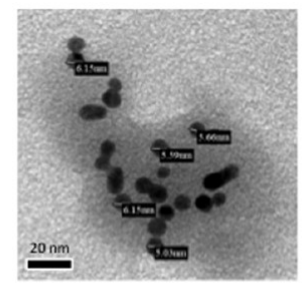

B

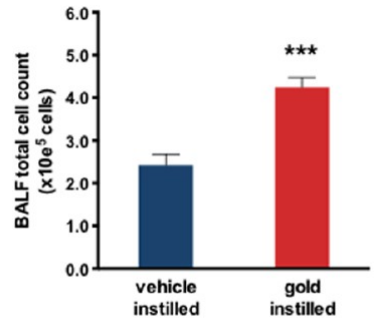

C
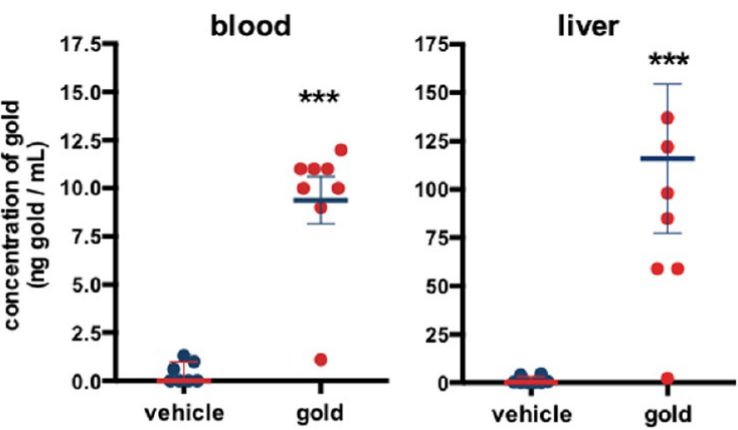

D

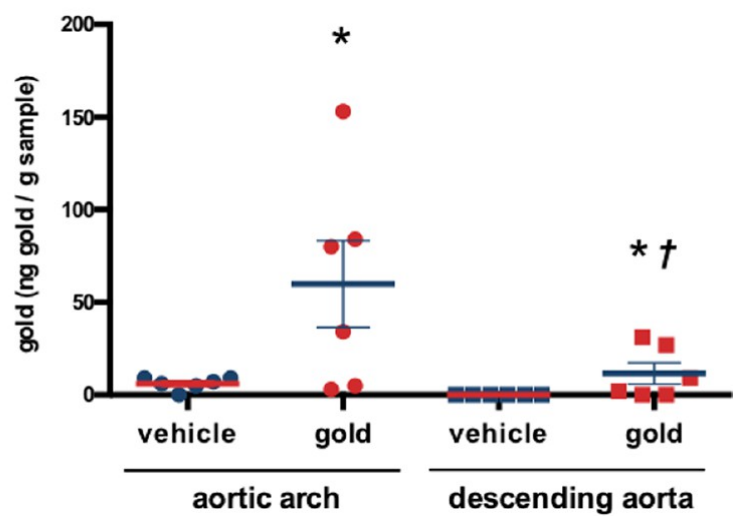

Figure 3. Accumulation of gold nanoparticles in tissues of $\mathrm{ApoE}^{-/-}$ mice following pulmonary instillation. (A) Transmission electron micrograph of gold particles used for instillations in mice, with a primary particle size of $5 \mathrm{~nm}$ and a median agglomerate size of 7.8 nm. (B) Instillation of gold nanoparticles caused mild lung inflammation, measured as total cell count in BALF. Mean \pm SEM, $* * * P<0.001$, unpaired $t$-test, $n=6$. (C) Gold was detectable in the blood and liver of gold-treated apolipoprotein-E knockout $\left(\mathrm{ApoE}^{-/-}\right)$mice. (D) Gold particles accumulated in areas of the vasculature rich in atheroma (aortic arch) compared to those free of plaque (descending aorta). Mean \pm SEM, $n=7-8$ (preclinical study). $* P<0.05, * * * P<0.001$, Mann-Whitney test compared to vehicle-treated animals, ${ }^{\dagger} P<0.05$, Mann-Whitney test compared to aortic arch of gold-treated mice.

following gold exposure (Supplementary Figure S4). Raman microscopy identified the presence of gold in the excised carotid plaque of those patients exposed to gold nanoparticles, but not in those without prior exposure (Figure 6B,C).

Here we demonstrate that inhaled nanoparticles translocate from the lung into the circulation in man, where they accumulate at sites of vascular inflammation. Particle translocation was size dependent, with greater translocation and accumulation of smaller nanoparticles. These observations suggest a direct role of particle size for inhaled nanoparticles in the pathogenesis of cardiovascular disease and provide a mechanism whereby exposure to combustion-derived nano- 

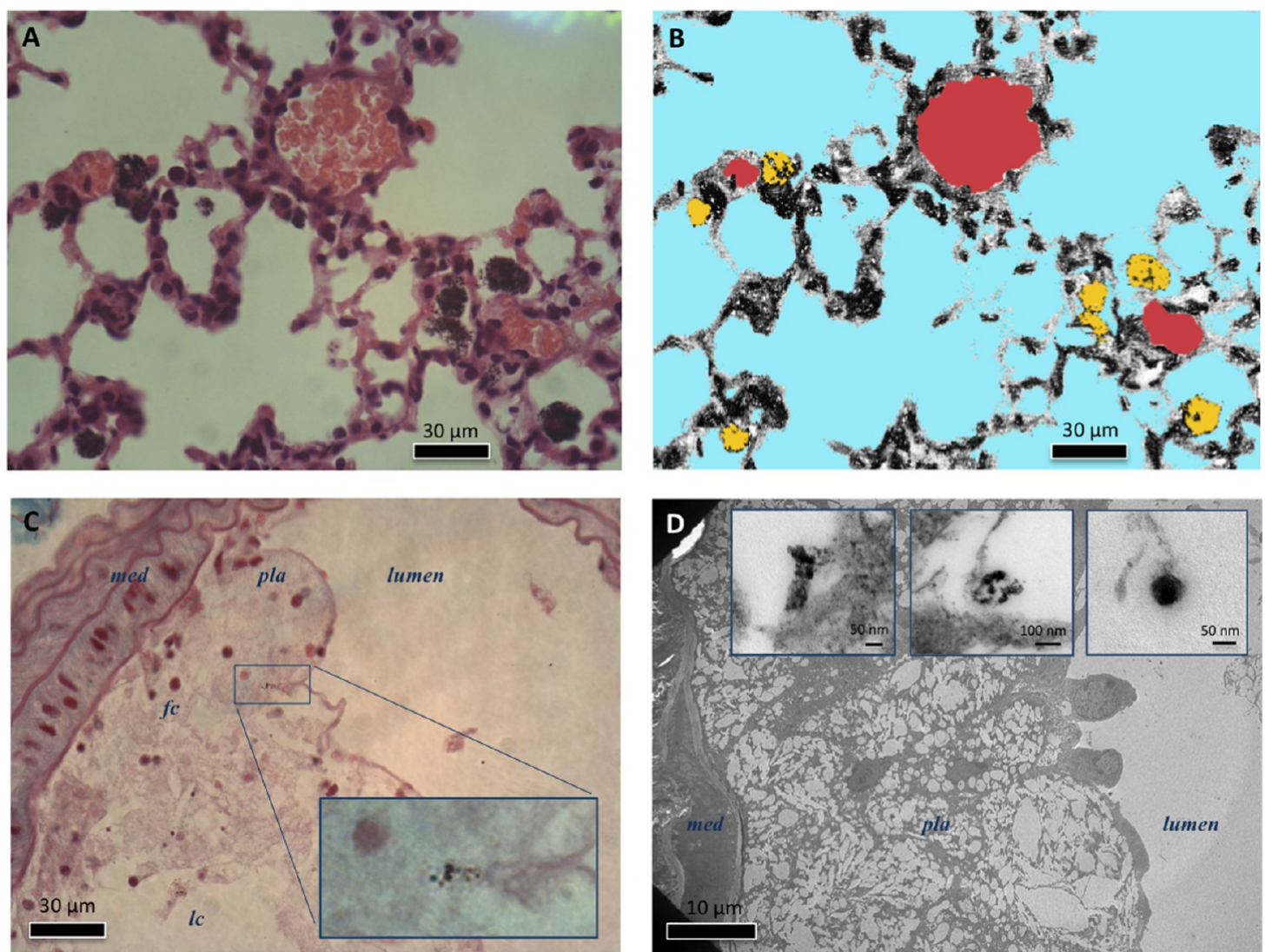

Figure 4. Visualization of gold nanoparticles in the lung and atherosclerotic plaques of $\mathrm{ApoE}^{-/-}$mice. (A) Gold particles were clearly visible within lungs of gold-treated animals, largely within alveolar macrophages. (B) Computational coloring to illustrate capillaries (red), alveolar spaces (blue), and gold particles (yellow). (C) Section of atherosclerotic plaque from a gold-treated mouse showing a distinctive cluster of red-purple granules within a macrophage-derived foam cell. (D) Transmission electron micrograph of atherosclerotic plaque within the aortic arch. Insets: examples of particle clusters within the plaques of gold-treated mice; med $=$ vascular media, pla $=$ atherosclerotic plaque, lumen $=$ blood vessel lumen, $f \mathfrak{c}=$ foam cell, $l c=$ lipid core.

particles and manufactured nanoparticles may promote atherosclerosis and trigger acute cardiovascular events.

Evaluation of nanoparticle translocation following inhalation exposure is challenging. Nemmar and colleagues previously demonstrated the presence of $99 \mathrm{~m}$ technetium $(99 \mathrm{mTc})$ in the bloodstream of healthy volunteers as early as $1 \mathrm{~min}$ after inhalation of $99 \mathrm{mTc}$-labeled carbon nanoparticles. ${ }^{24}$ However, subsequent studies could not replicate this finding, ${ }^{30,25}$ suggesting that soluble pertechnate salts, rather than nanoparticle translocation, accounted for the early and rapid detection of radioactivity in the blood. We used insoluble gold nanoparticles as they are a similar size to combustionderived nanoparticles, have low biological activity, and have been used safely in man as a radio-contrast agent and for drug delivery. ${ }^{31}$ Endogenous levels of gold in biological samples are negligible, ${ }^{32}$ permitting reliable identification and quantification of translocated gold at nanogram levels using high-resolution inductively coupled plasma mass spectroscopy (HR-ICPMS) and Raman microscopy.

Our findings suggest that translocation of nanoparticles into the circulation occurs rapidly, consistent with translocation via a passive transport mechanism, with a slow incremental accumulation in systemic tissues. There was no evidence of a time-dependent increase in gold concentration in the blood, suggesting that while gold nanoparticles translocate into the circulation, this is balanced by clearance. Indeed, gold was detected in the urine of almost all subjects within $24 \mathrm{~h}$ at a mean concentration of $35 \pm 24 \mathrm{ng} / \mathrm{mL}$. Based on the exposure characteristics of our first study $\left(2 \mathrm{~h}\right.$ exposure of $\sim 116 \mu \mathrm{g} / \mathrm{m}^{3}$ under light exercise), we calculate the total inhaled dose of particulate to be $\sim 690 \mu \mathrm{g}$. If $\sim 80 \mathrm{ng}$ of gold was cleared by the kidneys over $24 \mathrm{~h}$ (average volume of urine collected: $2.4 \mathrm{~L}$ containing $35 \mathrm{ng} / \mathrm{mL}$ ), and, therefore, if this was the sole route of clearance, we estimate that at least $0.2 \%$ of inhaled gold nanoparticles translocated from the lung into circulation. This estimate is consistent with those derived from pulmonary instillation of particles in animal models, ${ }^{33,34}$ and those derived from in vitro-in silico modeling. ${ }^{35}$ The majority of inhaled nanoparticles are retained in the alveolar region and are slowly cleared over time. ${ }^{25}$ In the present study, gold was still detectable in blood and urine at 3 months, consistent with ongoing translocation of gold either through the alveolar membrane or possibly via the gastrointestinal tract after clearance by the mucociliary escalator. These findings are consistent with those of Kreyling and colleagues ${ }^{36,37}$ who demonstrated the persistence of radiolabeled iridium nanoparticles in the lung 6 months after a $1 \mathrm{~h}$ inhalation in rats, with detectable levels in extra-pulmonary organs at this time.

The physicochemical properties of the particle that permit translocation will have important implications both for environmental particulates and manufactured nanomaterials. Particle size is one of the most crucial parameters affecting the biokinetics and subsequent actions of nanoparticles. ${ }^{38,39}$ Here we demonstrate in man that there is less translocation of gold 
A

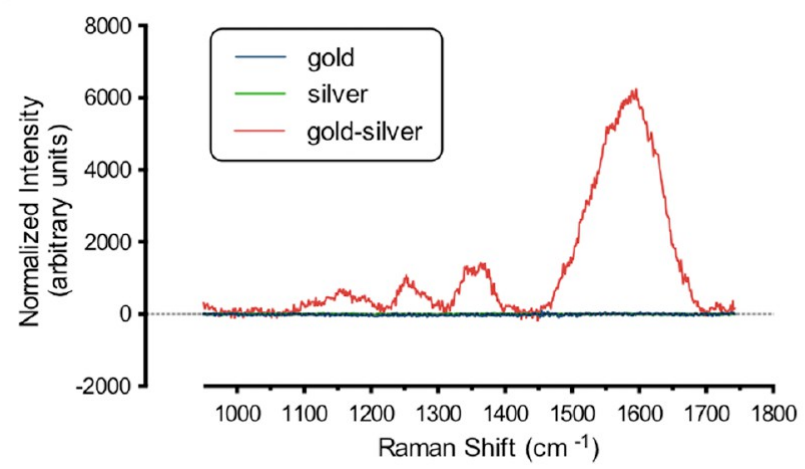

C



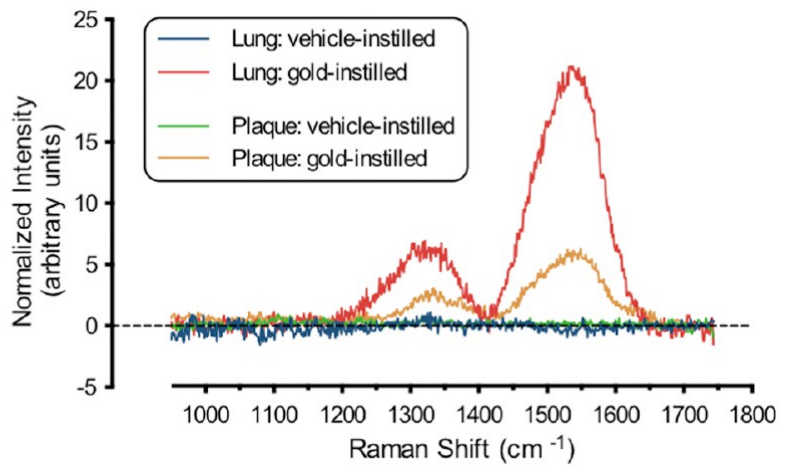

D

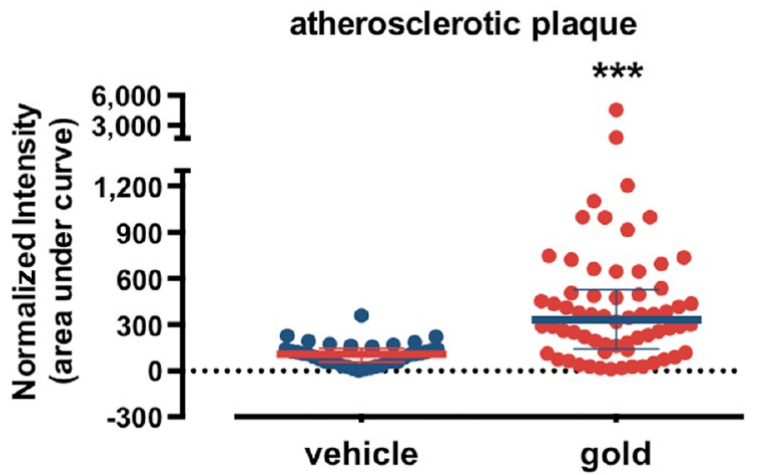

Figure 5. Raman spectroscopy to confirm the presence of particulate gold in lung and atherosclerotic plaques of ApoE ${ }^{-/-} \mathrm{mice}$ (A) Suspensions of gold nanoparticles following conjugation with silver produced a unique Raman spectra (red) that was not seen with either gold (blue) or silver alone (green). (B) Representative Raman spectra from silver-augmented gold in sections of lung (red) and atherosclerotic plaques (orange) from a gold-treated mouse, not seen in lung (blue) or plaque (green) sections from a vehicle-treated mouse. Raman spectra from (C) lung and (D) atherosclerotic plaques. Data expressed as median \pm interquartile range. $* * * P<0.001$, Mann-Whitney test comparing gold-treated $(n=64$ grids from 3 mice) to vehicle-treated $(n=39$ grids from 2 mice) mice.

particles with a primary diameter of $34 \mathrm{~nm}$ in comparison to that of $4 \mathrm{~nm}$ particles $(\sim 55 \mathrm{~nm}$ and $\sim 18 \mathrm{~nm}$ aerodynamic diameter of agglomerates, respectively). Our studies in mice exploited the availability of gold nanoparticles with narrow size distributions to define more tightly whether a size threshold is present for extra-pulmonary translocation. Significant translocation into the circulation occurred only at primary particle sizes below $30 \mathrm{~nm}$, with an inverse association between size and blood levels below this. Others have shown a size-dependent association for translocation of nanoparticles into the blood of healthy rats $^{40}$ that was balanced with clearance by the kidneys. ${ }^{41}$ The current studies suggest that clearance from the circulation via the kidney may have a smaller size threshold $(<6$ $\mathrm{nm}),{ }^{42,43}$ supporting the data of Balasubramanian et al. ${ }^{39}$ Thus, reliance on estimates of particle concentrations in the blood alone represents only a "snapshot" of several processes (alveolar deposition, epithelial and endothelial cell penetration, particle translocation, clearance via the kidneys, uptake into other tissues such as the liver, etc.), each with their own conditions for particle passage or retention. Particle surface charge $^{41,35}$ and protein interactions ${ }^{44,45}$ will also be important to translocation and clearance processes. Similarly, the ability of the inhaled particulate to induce pulmonary inflammation could alter translocation rates via increases in alveolar permeability ${ }^{46}$ or raised numbers of alveolar leucocytes that theoretically represent nonpassive carriers to assist translocation. These pathways are the subject of ongoing investigations.

The fate of inhaled nanoparticles that translocate into the circulation remains to be fully established. Recently, uptake of 7 or $20 \mathrm{~nm}$ nanoparticles in the aorta following prolonged inhalation (15 days) was reported in healthy rats. ${ }^{39}$ The potential for engineered nanoparticles (ultrasmall superparamagnetic particles of iron oxide, $\sim 30 \mathrm{~nm}$ particles) to accumulate at sites of inflammation, including atherosclerotic plaques, has been considered, but only following intravenous injection. ${ }^{47}$ In the present study, we administered nanoparticles via the lung of a well-validated mouse model of atherosclerosis. Gold was detected in high concentrations in the liver, confirming the liver as a primary route of clearance following translocation. Importantly, nanoparticles also accumulated at sites of vascular inflammation, but not in nonatherosclerotic blood vessels. The translocation and accumulation of gold nanoparticles in atherosclerotic plaque were confirmed in man. While the small sample size did not permit comparison of the extent of translocation between patients and healthy controls, Raman microscopy was sufficiently sensitive to detect particulate gold in carotid plaque. The cellular and kinetic mechanisms, as well as the particle characteristics, that determine the way circulating nanoparticles accumulate with atherosclerotic plaques require further investigation, although rheological conditions and inflammatory cells are likely to play a significant role in particle accumulation at sites of disease.

If inhaled nanoparticles are to alter the pathogenesis of atherosclerosis directly, then particles need to access susceptible sites and have the necessary physiochemical properties to induce toxicity. Our current studies required the use of an inert and identifiable nanoparticle, thus we could not address the pathobiological consequences of translocated nanoparticles 
A
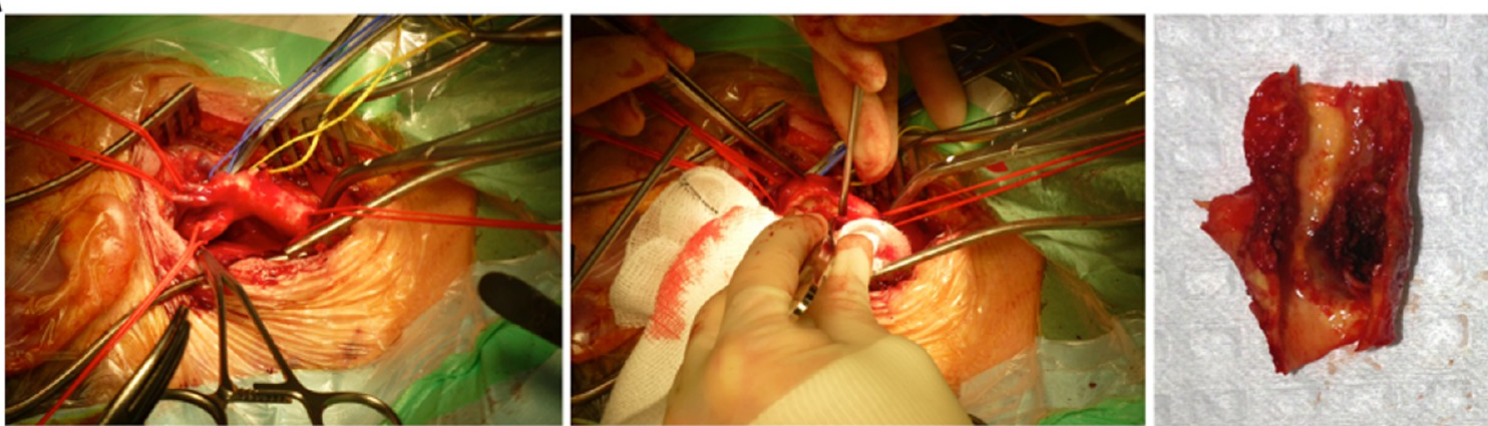

B

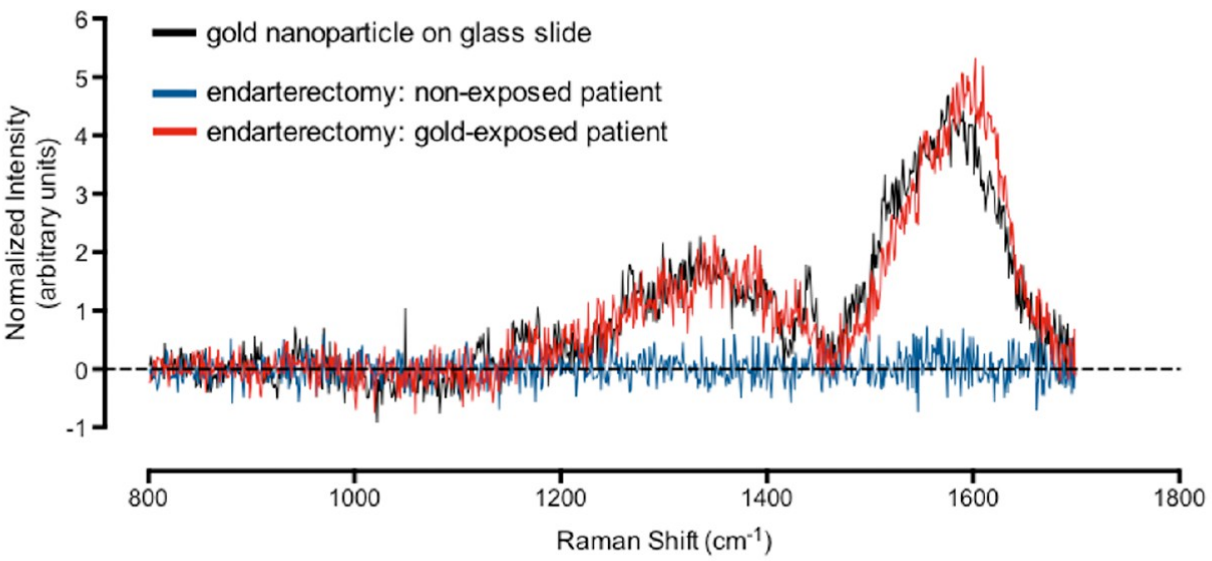

C
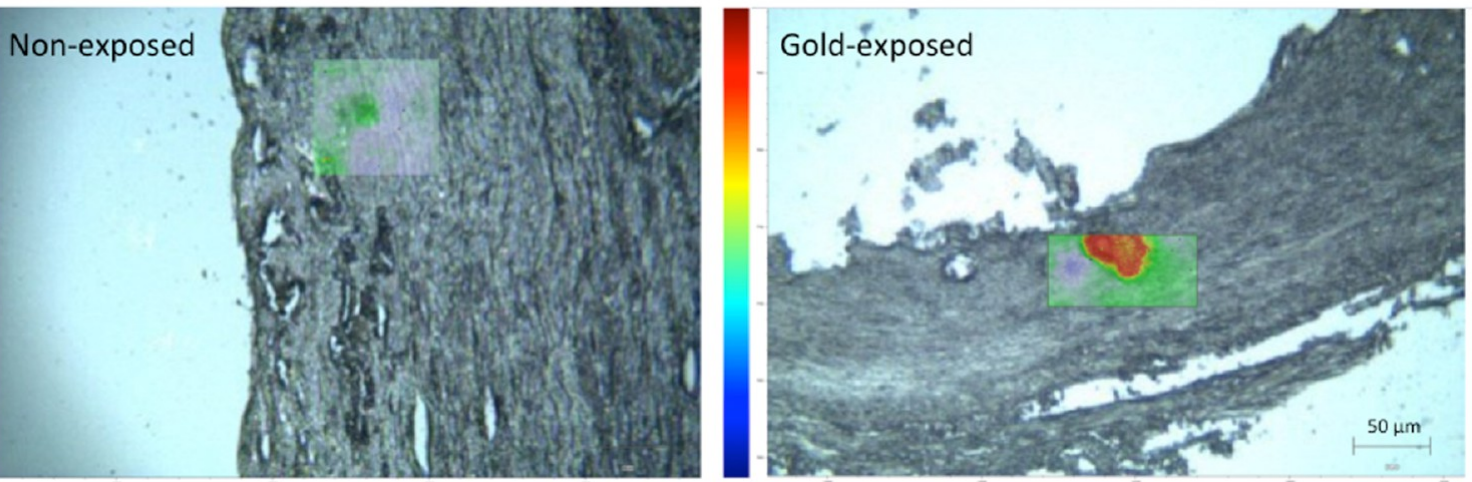

Figure 6. Gold nanoparticle exposures in patients undergoing carotid endarterectomy. (A) Isolation of atherosclerotic plaque from the carotid artery. (B) Overlaid representative Raman spectroscopy spectra: black = silver-stained spark-generated gold nanoparticles on glass slide (no tissue); blue = silver-stained endarterectomy sample from nonexposed patient; and red = silver-stained endarterectomy sample from goldexposed patient. (C) Visualization of gold in endarterectomy samples using heat-map of Raman intensity. Highlighted box within tissue denotes scanned area, with blue-green color representing baseline intensity (no gold) and red color showing high Raman intensity (gold particulate).

taken up into atherosclerotic plaques. Indeed, repeated instillation of gold nanoparticles did not increase the size of atherosclerotic plaques in the carotid of $\mathrm{ApoE}^{-/-}$mice. However, combustion-derived nanoparticles are known to induce oxidative stress and promote inflammation, and as such, are likely to directly promote atherosclerosis should they translocate and deposit in the vessel wall. ${ }^{17}$ We cannot address whether the pro-atherosclerotic effects of exposure to air pollution are due to accumulation of combustion-derived nanoparticles at sites of vascular inflammation in the present study, but our observations suggest this is both plausible and likely if nanoparticles were to accumulate in sufficient numbers. Furthermore, if nanoparticles accumulate in areas of inflam- mation elsewhere in the body, this could have important implications for other diseases, ${ }^{48}$ the potential for particles to cross the placental barrier during pregnancy, ${ }^{49,50}$ as well as the progression of, and theranostics for, cancer. ${ }^{51}$

These findings have immediate relevance for the nanotechnology industry where a diverse range of engineered nanomaterials is being developed for an ever-increasing number of applications. The fate of engineered nanoparticles and effect on health following exposure are largely unknown, ${ }^{1,2}$ especially in relation to the cardiovascular system. ${ }^{4}$ These studies use gold nanoparticles, a commonly used nanoparticle, and one that is being developed for clinical therapeutics. However, the biokinetics we observe here for gold may also extend to 
other nanomaterials including those with greater surface reactivity. Different classes of nanomaterials vary greatly in their ability to cause inflammation and cytotoxicity, thus it follows that there will be marked differences in their impact on health in both occupational settings and in the wider community exposed to nanomaterials. While data are still relatively sparse, a number of studies suggest that pulmonary exposure to a range of different inhaled nanoparticles may promote cardiovascular disease. ${ }^{4,52,53}$ A better understanding of how nanomaterials cross physiological barriers, and their fate thereafter, will be vital to allow for a safe-by-design approach for new nanomaterials.

\section{CONCLUSIONS}

We demonstrate that nanoparticles translocate from the lung to the circulation and selectively accumulate at sites of vascular inflammation in both animal models of disease and in man. These observations suggest that the fate of inhaled nanoparticles, as well as their size, is crucial for their potential to affect cardiovascular disease adversely. A greater understanding of how nanoparticles translocate and accumulate at sites of disease is of paramount importance for the risk assessment of both environmental and engineered nanoparticles.

\section{METHODS}

Full methods and any associated references are available in the Supporting Information.

Clinical Studies. All subjects gave their written informed consent, and the studies were reviewed and approved by the local research ethics committee according with the Declaration of Helsinki.

Healthy male nonsmoking volunteers aged 18-35 (Supplementary Tables S1 and S2) were exposed to gold nanoparticles for $2 \mathrm{~h}$ via inhalation, during intermittent exercise, in a specially built humancontrolled exposure chamber (Supplementary Figure S1A,B). Gold nanoparticles $(\sim 5 \mathrm{~nm}$ primary diameter) were freshly generated from gold electrodes using a commercial spark generator (Palas CFG1000, Palas GmbH, Karlsruhe, Germany). In subsequent experiments, larger single spherical particles were generated by extending the residence time in argon via a growth loop to agglomerate particles, followed by thermal fusing of particles. Following exposure, volunteers were taken to the adjacent clinical research facility where blood samples were obtained before and after gold exposure and at predefined intervals. A $24 \mathrm{~h}$ urine sample was also taken, beginning immediately prior to exposure, from an empty bladder.

Patients presenting to the Lothian Stroke services with a recent acute cerebrovascular syndrome (transient ischemic attack, amaurosis fugax, or stroke) and scheduled for carotid endarterectomy were also recruited (Supplementary Table S3). Patients were exposed to gold nanoparticles for two periods of $2 \mathrm{~h}$ the day prior to their surgery, but were not requested to exercise. At surgery, the plaque was excised intact as part of a standard carotid endarterectomy and patch angioplasty. The specimen was then snap frozen in liquid nitrogen and transferred to a freezer for subsequent batch analysis.

Animal Studies. All experiments were performed according to the Animals (Scientific Procedures) Act 1986 (U.K. Home Office).

Male apolipoprotein $\mathrm{E}$ knockout $\left(\mathrm{ApoE}^{-/-}\right)$mice were fed a highfat (21\% fat) "Western diet" for 8 weeks. ${ }^{15}$ Gold nanoparticles in suspension (citrate-coated, primary particle size $5 \mathrm{~nm}$; BBInternational, U.K.; $50 \mu \mathrm{L}$ of $2.3 \mathrm{mg} / \mathrm{mL}$ ), or vehicle, were administered to the lungs of mice by instillation twice weekly for the last 5 weeks of feeding (Supplementary Figure S1C). In experiments exploring particle size, 2, 5, 10, 30, or $200 \mathrm{~nm}$ particles (BBInternational) were used as above, with the exception that stock solutions were diluted in order that all sizes were of an equivalent mass concentration $(0.8 \mathrm{mg} / \mathrm{mL})$.

Animals were euthanized $\sim 18 \mathrm{~h}$ after the last instillation. Blood samples from the vena cava and liver biopsies were taken and stored in soda lime digestion tubes at $-80{ }^{\circ} \mathrm{C}$. The lungs were cannulated via a small incision in the trachea and lavaged 3 times with $0.8 \mathrm{~mL}$ of sterile saline to collect bronchoalveolar lavage fluid for measurement of lung inflammation. The aortic arch area and descending thoracic aorta were cleaned of perivascular fat, rinsed in saline, blotted dry, and frozen at $-80{ }^{\circ} \mathrm{C}$ in digestion tubes. The aortic arch region is used as an area of vasculature with extensive atherosclerotic lesions of a mixed "complex" plaque phenotype, whereas the descending aorta is largely free of atherosclerotic plaques in mice at this end under this feeding regime. ${ }^{15}$

Quantification of Gold in Biological Samples using HRICPMS. Biological samples were completely dissolved in aqua regia $\left(\mathrm{HNO}_{3}\right.$ and $\left.\mathrm{HCl} ; 120{ }^{\circ} \mathrm{C}\right)$ and diluted with ultrapure water to a final volume of $10 \mathrm{~mL}$ before analysis for gold content using HR-ICPMS (Element XR, Thermo Fisher, Bremen, Germany). ${ }^{54,55}$ For quality control aspects on the relevant ultratrace level, two reference samples "SEROnorm Trace levels in blood" (supplied by C. N. Schmidt, Amsterdam, The Netherlands; Supplementary Table S4) were analyzed, using two different batch numbers. The methodological limit of quantification was $0.03 \mathrm{ng} / \mathrm{g}$ of blood, and the coefficient of variation was $5.5 \%$ for blood samples run in triplicate.

Detection and Visualization of Gold Nanoparticles in Biological Tissues. Samples of the aortic arch for transmission electron microscopy were fixed for $2 \mathrm{~h}$ in $3 \%$ glutaraldehyde and postfixed for $45 \mathrm{~min}$ in $1 \%$ osmium tetroxide. Ultrathin sections $(60$ $\mathrm{nm}$ thick) were cut from selected areas, stained in uranyl acetate and lead citrate, then viewed in a Phillips CM120 transmission electron microscope.

Biological samples were fixed in $10 \%$ neutral-buffered formalin before histological processing and stained with hematoxylin and eosin (lung) or United States Trichrome (arteries). Atherosclerotic burden was comprehensively assessed, as previously described. ${ }^{15}$ The carotid artery bifurcation was used to quantify atherosclerotic burden in goldtreated animals, as brachiocephalic arteries were used for detection of gold by HR-ICMPS.

Raman spectroscopy was performed using unstained histological sections that had been deparaffinized in graded alcohol. Detection of gold particulate was assisted by conjugation to silver using a LI-silver enhancement kit (Molecular Probes, Invitrogen, Paisley, U.K.). Tissue sections were incubated in $50 \mathrm{nM}$ of glycine in phosphate-buffered saline ( $\mathrm{pH} 7.4 ; 5 \mathrm{~min})$ to block aldehyde groups in the fixation reagent, then thoroughly rinsed with $\mathrm{dH}_{2} \mathrm{O}$ to remove all traces of phosphate ions from PBS. Silver staining reagents were added for 5 min before washing with water and leaving to air dry.

Detection of gold within tissue samples was performed by Raman spectroscopy (Renishaw inVia, Renishaw U.K.). Raman spectra from the lung tissue sections were collected with exposure time of $60 \mathrm{~s}$ and $10 \%$ laser power, at $514 \mathrm{~nm}$. Spectra were quantified by transforming data to area under the curve (spectra) between a Raman shift of 950$1750 \mathrm{~cm}^{-1}$.

Data Analysis. For parametric data (Gaussian distribution) values reported are mean \pm SEM with differences between groups analyzed by analysis of variance (ANOVA) with Bonferroni posthoc tests and Student's $t$-tests, where appropriate (GraphPad Prism v6.0a). For nonparametric (non-normally distributed) data, values are reported as median \pm interquartile range, with differences between groups analyzed by Kruskal-Wallis followed by Dunn's posthoc tests and Mann-Whitney tests. ROUT's outlier ${ }^{56}(Q=1 \%$, GraphPad Prism v6.0a) was used to detect the presence of outliers in conditions where normalization to very small tissue weights (aortic arch and descending aorta) skewed data sets. $P<0.05$ was taken as statistically significant.

\section{ASSOCIATED CONTENT}

\section{Supporting Information}

The Supporting Information is available free of charge on the ACS Publications website at DOI: 10.1021/acsnano.6b08551.

Supplementary Tables S1-S4 and Figures S1-S4 and full method descriptions (PDF) 


\section{AUTHOR INFORMATION}

\section{Corresponding Author}

*E-mail: mark.miller@ed.ac.uk.

\section{ORCID}

Mark R. Miller: 0000-0002-7078-597X

\section{Author Contributions}

${ }^{\infty}$ R.D. and N.L.M. had joint and equal contribution to senior authorship.

\section{Author Contributions}

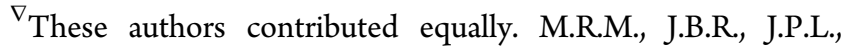
P.W.F.H., A.V., K.D., D.E.N., R.D. and N.L.M. conceived and designed the studies. M.R.M., J.B.R., S.G.M., and R.D. performed the animal studies and collected data. J.P.L. and S.W. performed the clinical studies. A.T.V. performed the studies in carotid endarterectomy patients. P.K. performed the HR-ICPMS analysis. P.S., J.R., S.C., and C.J.C. performed the Raman Spectroscopy. F.R.C., P.H.B.F., and A.J.F.B. generated the gold exposures for the clinical studies. J.P.L., M.R.M., J.B.R., and N.L.M. performed data analysis. M.R.M., J.P.L., and N.L.M. drafted the manuscript.

\section{Notes}

The authors declare no competing financial interest.

\section{ACKNOWLEDGMENTS}

We would like to thank S. McSheaffrey and J. Sethunarayanan for their assistance with the clinical studies as well as the nursing staff at the Clinical Research Facility, Royal Infirmary of Edinburgh, which is supported by NHS Research Scotland (NRS) through NHS Lothian. We thank S. Mitchell for his technical assistance with the electron microscopy and E. Miller for her assistance with the histological analysis. Thanks also to B. Stolpe at University of Birmingham Facility for Environmental Nanoscience Analysis and Characterisation (FENAC) for his help with the characterization of the gold nanoparticles. This research was supported by Programme and Project Grants from the British Heart Foundation (RG/10/9/28286; PG/10/ 042/28388; PG/12/8/29371) and a Project Grant (202111) from the COLT Foundation, with additional support from the Dutch Ministry of Infrastructures and Environment (M/ 630196) and the U.K. Department of Health (PR-NT-020810025). M.R.M., N.L.M., and D.E.N. are supported by a Special Project Grant (SP/15/8/31575), the Butler Senior Clinical Research Fellowship (FS/16/14/32023), and a Chair Award ( $\mathrm{CH} / 09 / 002)$, respectively, from the British Heart Foundation. D.E.N. is the recipient of a Wellcome Trust Senior Investigator Award (WT103782AIA).

\section{REFERENCES}

(1) Malysheva, A.; Lombi, E.; Voelcker, N. H. Bridging the divide between human and environmental nanotoxicology. Nat. Nanotechnol. 2015, 10, 835-844.

(2) Valsami-Jones, E.; Lynch, I. NANOSAFETY. How safe are nanomaterials? Science 2015, 350, 388-389.

(3) Johnston, H.; Pojana, G.; Zuin, S.; Jacobsen, N. R.; Møller, P.; Loft, S.; Semmler-Behnke, M.; McGuiness, C.; Balharry, D.; Marcomini, A.; Wallin, H.; Kreyling, W.; Donaldson, K.; Tran, L.; Stone, V. Engineered nanomaterial risk. Lessons learnt from completed nanotoxicology studies: potential solutions to current and future challenges. Crit. Rev. Toxicol. 2013, 43, 1-20.

(4) Donaldson, K.; Duffin, R.; Langrish, J. P.; Miller, M. R.; Mills, N. L.; Poland, C. A.; Raftis, J.; Shah, A.; Shaw, C. A.; Newby, D. E. Nanoparticles and the cardiovascular system: a critical review. Nanomedicine (London, U. K.) 2013, 8, 403-423.
(5) World Health Organization. 7 million premature deaths annually linked to air pollution. http://www.who.int/mediacentre/news/ releases/2014/air-pollution/en/. Accessed on March 29, 2017.

(6) Newby, D. E.; Mannucci, P. M.; Tell, G. S.; Baccarelli, A. A.; Brook, R. D.; Donaldson, K.; Forastiere, F.; Franchini, M.; Franco, O. H.; Graham, I.; Hoek, G.; Hoffmann, B.; Hoylaerts, M. F.; Kunzli, N.; Mills, N.; Pekkanen, J.; Peters, A.; Piepoli, M. F.; Rajagopalan, S.; Storey, R. F. Esc Working Group on Thrombosis, E. A. f. C. P.; Rehabilitation; Association, E. S. C. H. F., Expert position paper on air pollution and cardiovascular disease. Eur. Heart J. 2015, 36, 83-93.

(7) Brook, R. D.; Rajagopalan, S.; Pope, C. A., 3rd; Brook, J. R.; Bhatnagar, A.; Diez-Roux, A. V.; Holguin, F.; Hong, Y.; Luepker, R. V.; Mittleman, M. A.; Peters, A.; Siscovick, D.; Smith, S. C., Jr.; Whitsel, L.; Kaufman, J. D. Particulate matter air pollution and cardiovascular disease: An update to the scientific statement from the American Heart Association. Circulation 2010, 121, 2331-2378.

(8) Shah, A. S.; Lee, K. K.; McAllister, D. A.; Hunter, A.; Nair, H.; Whiteley, W.; Langrish, J. P.; Newby, D. E.; Mills, N. L. Short term exposure to air pollution and stroke: systematic review and metaanalysis. BMJ. 2015, 350, h1295.

(9) Peters, A.; Dockery, D. W.; Muller, J. E.; Mittleman, M. A. Increased particulate air pollution and the triggering of myocardial infarction. Circulation 2001, 103, 2810-5.

(10) Nel, A. Atmosphere. Air pollution-related illness: effects of particles. Science 2005, 308, 804-806.

(11) Kelly, F. J.; Zhu, T. Transport solutions for cleaner air. Science 2016, 352, 934-936.

(12) Lucking, A. J.; Lundback, M.; Mills, N. L.; Faratian, D.; Barath, S. L.; Pourazar, J.; Cassee, F. R.; Donaldson, K.; Boon, N. A.; Badimon, J. J.; Sandstrom, T.; Blomberg, A.; Newby, D. E. Diesel exhaust inhalation increases thrombus formation in man. Eur. Heart J. 2008, 29, 3043-3051.

(13) Mills, N. L.; Tornqvist, H.; Robinson, S. D.; Gonzalez, M.; Darnley, K.; MacNee, W.; Boon, N. A.; Donaldson, K.; Blomberg, A.; Sandstrom, T.; Newby, D. E. Diesel exhaust inhalation causes vascular dysfunction and impaired endogenous fibrinolysis. Circulation 2005, 112 , 3930-3936.

(14) Sun, Q.; Wang, A.; Jin, X.; Natanzon, A.; Duquaine, D.; Brook, R. D.; Aguinaldo, J. G.; Fayad, Z. A.; Fuster, V.; Lippmann, M.; Chen, L. C.; Rajagopalan, S. Long-term air pollution exposure and acceleration of atherosclerosis and vascular inflammation in an animal model. JAMA 2005, 294, 3003-3010.

(15) Miller, M. R.; McLean, S. G.; Duffin, R.; Lawal, A. O.; Araujo, J. A.; Shaw, C. A.; Mills, N. L.; Donaldson, K.; Newby, D. E.; Hadoke, P. W. Diesel exhaust particulate increases the size and complexity of lesions in atherosclerotic mice. Part. Fibre Toxicol. 2013, 10, 61.

(16) Donaldson, K.; Tran, L.; Jimenez, L. A.; Duffin, R.; Newby, D. E.; Mills, N.; MacNee, W.; Stone, V. Combustion-derived nanoparticles: a review of their toxicology following inhalation exposure. Part. Fibre Toxicol. 2005, 2, 10.

(17) Miller, M. R.; Shaw, C. A.; Langrish, J. P. From particles to patients: oxidative stress and the cardiovascular effects of air pollution. Future Cardiol. 2012, 8, 577-602.

(18) Seaton, A.; MacNee, W.; Donaldson, K.; Godden, D. Particulate air pollution and acute health effects. Lancet 1995, 345, 176-178.

(19) Mills, N. L.; Donaldson, K.; Hadoke, P. W.; Boon, N. A.; MacNee, W.; Cassee, F. R.; Sandstrom, T.; Blomberg, A.; Newby, D. E. Adverse cardiovascular effects of air pollution. Nat. Clin. Pract. Cardiovasc. Med. 2009, 6, 36-44.

(20) Husain, M.; Wu, D.; Saber, A. T.; Decan, N.; Jacobsen, N. R.; Williams, A.; Yauk, C. L.; Wallin, H.; Vogel, U.; Halappanavar, S. Intratracheally instilled titanium dioxide nanoparticles translocate to heart and liver and activate complement cascade in the heart of C57BL/6 mice. Nanotoxicology 2015, 9, 1013-1022.

(21) Hussain, S.; Vanoirbeek, J. A.; Haenen, S.; Haufroid, V.; Boland, S.; Marano, F.; Nemery, B.; Hoet, P. H. Prior lung inflammation impacts on body distribution of gold nanoparticles. BioMed Res. Int. 2013, 2013, 923475 . 
(22) Rothen-Rutishauser, B.; Muhlfeld, C.; Blank, F.; Musso, C.; Gehr, P. Translocation of particles and inflammatory responses after exposure to fine particles and nanoparticles in an epithelial airway model. Part. Fibre Toxicol. 2007, 4, 9.

(23) Meiring, J. J.; Borm, P. J.; Bagate, K.; Semmler, M.; Seitz, J.; Takenaka, S.; Kreyling, W. G. The influence of hydrogen peroxide and histamine on lung permeability and translocation of iridium nanoparticles in the isolated perfused rat lung. Part. Fibre Toxicol. 2005, 2, 3.

(24) Nemmar, A.; Hoet, P. H.; Vanquickenborne, B.; Dinsdale, D.; Thomeer, M.; Hoylaerts, M. F.; Vanbilloen, H.; Mortelmans, L.; Nemery, B. Passage of inhaled particles into the blood circulation in humans. Circulation 2002, 105, 411-414.

(25) Möller, W.; Felten, K.; Sommerer, K.; Scheuch, G.; Meyer, G.; Meyer, P.; Haussinger, K.; Kreyling, W. G. Deposition, retention, and translocation of ultrafine particles from the central airways and lung periphery. Am. J. Respir. Crit. Care Med. 2008, 177, 426-432.

(26) Kreyling, W. G.; Semmler, M.; Erbe, F.; Mayer, P.; Takenaka, S.; Schulz, H.; Oberdorster, G.; Ziesenis, A. Translocation of ultrafine insoluble iridium particles from lung epithelium to extrapulmonary organs is size dependent but very low. J. Toxicol. Environ. Health, Part A 2002, 65, 1513-1530.

(27) Choi, H. S.; Ashitate, Y.; Lee, J. H.; Kim, S. H.; Matsui, A.; Insin, N.; Bawendi, M. G.; Semmler-Behnke, M.; Frangioni, J. V.; Tsuda, A. Rapid translocation of nanoparticles from the lung airspaces to the body. Nat. Biotechnol. 2010, 28, 1300-1303.

(28) Oberdorster, G.; Sharp, Z.; Atudorei, V.; Elder, A.; Gelein, R.; Lunts, A.; Kreyling, W.; Cox, C. Extrapulmonary translocation of ultrafine carbon particles following whole-body inhalation exposure of rats. J. Toxicol. Environ. Health, Part A 2002, 65, 1531-1543.

(29) Hirn, S.; Semmler-Behnke, M.; Schleh, C.; Wenk, A.; Lipka, J.; Schaffler, M.; Takenaka, S.; Möller, W.; Schmid, G.; Simon, U.; Kreyling, W. G. Particle size-dependent and surface charge-dependent biodistribution of gold nanoparticles after intravenous administration. Eur. J. Pharm. Biopharm. 2011, 77, 407-416.

(30) Mills, N. L.; Amin, N.; Robinson, S. D.; Anand, A.; Davies, J.; Patel, D.; de la Fuente, J. M.; Cassee, F. R.; Boon, N. A.; Macnee, W.; Millar, A. M.; Donaldson, K.; Newby, D. E. Do inhaled carbon nanoparticles translocate directly into the circulation in humans? Am. J. Respir. Crit. Care Med. 2006, 173, 426-431.

(31) Thakor, A. S.; Jokerst, J.; Zavaleta, C.; Massoud, T. F.; Gambhir, S. S. Gold nanoparticles: a revival in precious metal administration to patients. Nano Lett. 2011, 11, 4029-4036.

(32) Heitland, P.; Koster, H. D. Biomonitoring of 37 trace elements in blood samples from inhabitants of northern Germany by ICP-MS. J. Trace Elem. Med. Biol. 2006, 20, 253-262.

(33) Semmler-Behnke, M.; Kreyling, W. G.; Lipka, J.; Fertsch, S.; Wenk, A.; Takenaka, S.; Schmid, G.; Brandau, W. Biodistribution of 1.4- and 18-nm gold particles in rats. Small 2008, 4, 2108-2111.

(34) Takenaka, S.; Karg, E.; Kreyling, W. G.; Lentner, B.; Möller, W.; Behnke-Semmler, M.; Jennen, L.; Walch, A.; Michalke, B.; Schramel, P.; Heyder, J.; Schulz, H. Distribution pattern of inhaled ultrafine gold particles in the rat lung. Inhalation Toxicol. 2006, 18, 733-740.

(35) Bachler, G.; Losert, S.; Umehara, Y.; von Goetz, N.; RodriguezLorenzo, L.; Petri-Fink, A.; Rothen-Rutishauser, B.; Hungerbuehler, K. Translocation of gold nanoparticles across the lung epithelial tissue barrier: Combining in vitro and in silico methods to substitute in vivo experiments. Part. Fibre Toxicol. 2015, 12, 18.

(36) Semmler, M.; Seitz, J.; Erbe, F.; Mayer, P.; Heyder, J.; Oberdorster, G.; Kreyling, W. G. Long-term clearance kinetics of inhaled ultrafine insoluble iridium particles from the rat lung, including transient translocation into secondary organs. Inhalation Toxicol. 2004, $16,453-459$.

(37) Semmler-Behnke, M.; Takenaka, S.; Fertsch, S.; Wenk, A.; Seitz, J.; Mayer, P.; Oberdorster, G.; Kreyling, W. G. Efficient elimination of inhaled nanoparticles from the alveolar region: evidence for interstitial uptake and subsequent reentrainment onto airways epithelium. Environ. Health Perspect. 2007, 115, 728-733.
(38) Nakane, H. Translocation of particles deposited in the respiratory system: a systematic review and statistical analysis. Environ. Health Prev. Med. 2012, 17, 263-274.

(39) Balasubramanian, S. K.; Poh, K. W.; Ong, C. N.; Kreyling, W. G.; Ong, W. Y.; Yu, L. E. The effect of primary particle size on biodistribution of inhaled gold nano-agglomerates. Biomaterials 2013, $34,5439-5452$

(40) Sadauskas, E.; Jacobsen, N. R.; Danscher, G.; Stoltenberg, M.; Vogel, U.; Larsen, A.; Kreyling, W.; Wallin, H. Biodistribution of gold nanoparticles in mouse lung following intratracheal instillation. Chem. Cent. J. 2009, 3, 16.

(41) Kreyling, W. G.; Hirn, S.; Möller, W.; Schleh, C.; Wenk, A.; Celik, G.; Lipka, J.; Schaffler, M.; Haberl, N.; Johnston, B. D.; Sperling, R; Schmid, G.; Simon, U.; Parak, W. J.; Semmler-Behnke, M. Airblood barrier translocation of tracheally instilled gold nanoparticles inversely depends on particle size. ACS Nano 2014, 8, 222-233.

(42) Sarin, H. Physiologic upper limits of pore size of different blood capillary types and another perspective on the dual pore theory of microvascular permeability. J. Angiog. Res. 2010, 2, 14.

(43) Choi, H. S.; Liu, W.; Misra, P.; Tanaka, E.; Zimmer, J. P.; Itty Ipe, B.; Bawendi, M. G.; Frangioni, J. V. Renal clearance of quantum dots. Nat. Biotechnol. 2007, 25, 1165-1170.

(44) Kreyling, W. G.; Fertsch-Gapp, S.; Schaffler, M.; Johnston, B. D.; Haberl, N.; Pfeiffer, C.; Diendorf, J.; Schleh, C.; Hirn, S.; SemmlerBehnke, M.; Epple, M.; Parak, W. J. In vitro and in vivo interactions of selected nanoparticles with rodent serum proteins and their consequences in biokinetics. Beilstein J. Nanotechnol. 2014, 5, 16991711.

(45) Kim, K. J.; Malik, A. B. Protein transport across the lung epithelial barrier. Am. J. Physiol. Lung Cell. Mol. Physiol. 2003, 284, L247-L259.

(46) Chen, J.; Tan, M.; Nemmar, A.; Song, W.; Dong, M.; Zhang, G.; $\mathrm{Li}, \mathrm{Y}$. Quantification of extrapulmonary translocation of intratrachealinstilled particles in vivo in rats: effect of lipopolysaccharide. Toxicology 2006, 222, 195-201.

(47) Kooi, M. E.; Cappendijk, V. C.; Cleutjens, K. B.; Kessels, A. G.; Kitslaar, P. J.; Borgers, M.; Frederik, P. M.; Daemen, M. J.; van Engelshoven, J. M. Accumulation of ultrasmall superparamagnetic particles of iron oxide in human atherosclerotic plaques can be detected by in vivo magnetic resonance imaging. Circulation 2003, 107, 2453-2458.

(48) El-Ansary, A.; Al-Daihan, S.; Bacha, A. B.; Kotb, M. Toxicity of novel nanosized formulations used in medicine. Methods Mol. Biol. 2013, 1028, 47-74.

(49) Semmler-Behnke, M.; Lipka, J.; Wenk, A.; Hirn, S.; Schaffler, M.; Tian, F.; Schmid, G.; Oberdorster, G.; Kreyling, W. G. Size dependent translocation and fetal accumulation of gold nanoparticles from maternal blood in the rat. Part. Fibre Toxicol. 2014, 11, 33.

(50) Keelan, J. A. Nanotoxicology: nanoparticles versus the placenta. Nat. Nanotechnol. 2011, 6, 263-264.

(51) Davis, M. E.; Chen, Z. G.; Shin, D. M. Nanoparticle therapeutics: an emerging treatment modality for cancer. Nat. Rev. Drug Discovery 2008, 7, 771-782.

(52) Li, Z.; Hulderman, T.; Salmen, R.; Chapman, R.; Leonard, S. S.; Young, S. H.; Shvedova, A.; Luster, M. I.; Simeonova, P. P. Cardiovascular effects of pulmonary exposure to single-wall carbon nanotubes. Environ. Health Perspect. 2007, 115, 377-382.

(53) Chen, T.; Hu, J.; Chen, C.; Pu, J.; Cui, X.; Jia, G. Cardiovascular effects of pulmonary exposure to titanium dioxide nanoparticles in ApoE knockout mice. J. Nanosci. Nanotechnol. 2013, 13, 3214-3222.

(54) Krystek, P.; Ritsema, R. Validation assessment about the determination of selected elements in groundwater by high-resolution inductively coupled plasma mass spectrometry (HR-ICPMS). Int. J. Environ. Anal. Chem. 2009, 89, 331-345.

(55) Lankveld, D. P.; Rayavarapu, R. G.; Krystek, P.; Oomen, A. G.; Verharen, H. W.; van Leeuwen, T. G.; De Jong, W. H.; Manohar, S. Blood clearance and tissue distribution of PEGylated and nonPEGylated gold nanorods after intravenous administration in rats. Nanomedicine (London, U. K.) 2011, 6, 339-349. 
(56) Motulsky, H. J.; Brown, R. E. Detecting outliers when fitting data with nonlinear regression - a new method based on robust nonlinear regression and the false discovery rate. BMC Bioinf. 2006, 7,

123. 